\title{
Review of Rollin's The Frankenstein Syndrome
}

\author{
Steve F. Sapontzis \\ California State University, Hayward
}

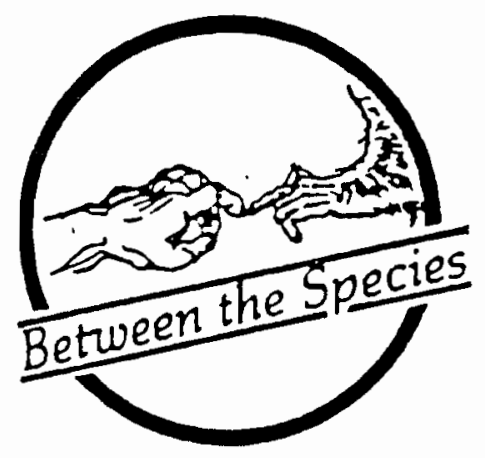

The Frankenstein Syndrome: Ethical and Social Issues in the Genetic Engineering of Animals by Bernard E. Rollin (Cambridge University Press, 1995: 239+xiv pages)

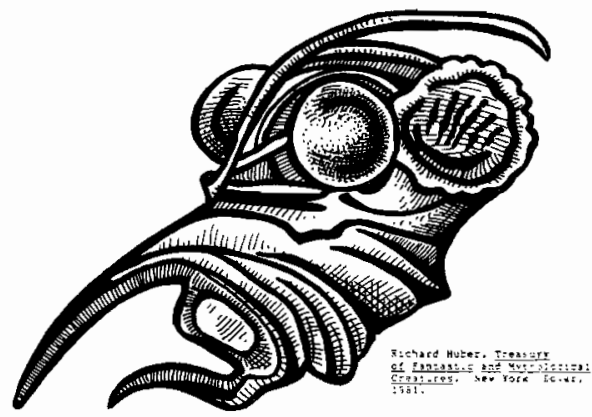

This book is a defense of genetic engineering against "the Frankenstein thing." In his brief Introduction, Rollin tells us that "the Frankenstein story strikes a socially responsive chord, providing us with a way of articulating our fears and doubts about science and technology" (3-4). Nothing wrong with that, but "when and if the myth becomes reified or transformed into or equated with reality, [it] conceals nuances, shades, and subtleties of what it represents....The myth is either accepted as literal truth or categorically rejected as nonsense, with little thought for the possibilities in between, where the truth surely lies" (4). In all his work on animal protection, Rollin has been an aggressive, articulate, and effective champion of such middle ground possibilities, so no one familiar with his work will be surprised to find that this book begins by energetically toppling abolitionist objections to genetic engineering then maps out procedures for guiding such engineering toward beneficial results. If Rollin is correct that "genetic engineering of animals cannot be stopped-it is too simple and relatively inexpensive to accomplish" (4), his middle ground approach is the only effective expression for our Frankensteinian fears.

In Chapter 1, Rollin deals with "the first version" of "the Frankenstein thing," the contention that genetic engineering is intrinsically wrong. "There are certain things humans were not meant to do" (vii), and genetic engineering is one of them. His targets here are the media, scientific ideology, Jeremy Rifkin, Holmes Rolston, and anthropocentric theology. In its drive to sell its product, the media is driven to package all issues in "small, provocative bits" that "can be dramatically presented as black-and-white extremes" (7). Such successful packaging supplants careful analyses of the ethical dimensions of social policy issues.

This is especially the case when those who are most familiar with the issue--because they are participants in it-contend that what they are doing is "value-free." Scientists are fond of making this claim, so they can busily go about doing science without having to bother with thinking about the morality of what they are doing. Rollin delivers the swift kick in the rear that this head-down, ass-up ostrich pose invites and deserves. Rollin argues that such scientists confuse the fact that the truth of scientific statements does not depend on moral values with the fantasy that the enterprise of science-what objectives are pursued by scientists and what procedures are employed in that pursuit-does not depend on moral values. What scientists do is never value-free, although many scientists adamantly refuse to examine the values

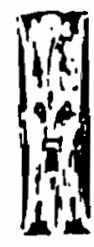

REVIEW

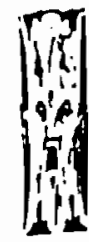


presupposed in what they do, preferring to busy themselves in the laboratory instead. Unfortunately, they thus abandon the field to uninformed criticism of what they are doing.

In the case of genetic engineering, one such criticism takes the form of contending that we should not play God, mess with nature, violate the sanctity of life, blur species distinctions, erode the special place of humans, and so forth. Rollin acknowledges that those who oppose genetic engineering on such grounds tend to present the wrongness of genetic engineering as self-evident, hence not in need of supporting argument. However, since these matters are not self-evident to him, Rollin looks for reasons that might lead one to conclude that genetic engineering is wrong irrespective of its consequences. In Jeremy Rifkin's work, he finds that genetic engineering is tarred with the brush of reductionism, i.e., viewing life as a bunch of chemicals. Rollin points out that there is no logical link between genetic engineering and reductionism. Rollin then considers the possibility that genetic engineering is incompatible with the mind-set necessary for producing the good life for human beings, because it emphasizes the physical and forgets the personal dimensions of human life. Again, he answers that there is no logical connection here; if genetic engineering produces this result, it is only because we will have failed to give our scientists adequate humanistic education-something we are, apparently, already failing to do.

Rollin concludes his critique of Rifkin on the same note with which he opens his critique of Rolston: the mystical value given to species cannot be justified. In the case of Rifkin, Rollin finds that he tries to have it both ways: he tries to be both a nominalist and a realist, blurring the difference in order to transfer the common sense value of separate individuals to separate species. In the case of Rolston, the confusions are several. First, he confuses our valuing things in themselves, as we do when we find them beautiful, with objective value, a value things would have in themselves regardless of whether anyone appreciated that value. Next Rolston commits a genetic fallacy by arguing that since humans, who are intrinsically valuable, are produced by nature, nature, too, must be intrinsically valuable. Finally, Rolston relies on a bad argument by analogy, arguing that since nonsentient nature is analogous to sentient beings, it has the same, intrinsic value as sentient beings. Rollin clearly finds attempts, like Rolston's, to give intrinsic value to nonsentient nature to be worthless, and, consequently, he also finds worthless those criticisms of genetic engineering based on its interference with supposedly intrinsically valuable elements of nature, such as species distinctions.

Finally, Rollin points out that mixing human and animal parts is already standard practice in modern medicine, with, for example, pig valves being used to combat human heart disease. His general conclusion is that claims that genetic engineering is intrinsically wrong rest on unjustifiable, pseudo-religious categories and confused, dualistic thinking. The real worries about genetic engineering are consequential, giving rise to the second version of the Frankenstein thing: "genetic engineering of animals, although while [ $\mathrm{sic}$ ] not wrong by its nature, is wrong because it is likely to produce significant harm" (66). Possible harm to humans is the subject of the second chapter of Rollin's book.

While Rollin's criticisms of putative "inherent" values are certainly well-taken, the reader may still come away from Chapter 1 feeling that there is more to be said in defense of this first version of "the Frankenstein thing." At least part of what is meant by saying that human individuals have "inherent" value is that they should not be treated as commodities to be routinely sacrificed if a cost/benefit analysis indicates that the interests of the group would be enhanced by such sacrifice. The genetic engineering of animals embodies the idea that animals lack this sort of inherent value, for the genetic engineering of animals suggests that animals are commodities that may be invasively manipulated and reconstructed in order to make the exploitation of them for human benefit more efficient and profitable for human exploiters. Consequently, the reader may regret that in this discussion, Rollin did not address some of the mainstream animal liberation arguments for ascribing this sort of "inherent" value to animals. (In Chapter 3, Rollin raises the possibility that genetic engineering might make "us more prone to treat animals merely as tools for human use rather than as 'ends in themselves,' whose fates matter to them as well as to us" (193).)

Chapter 2 is actually two chapters. The last seven sections of the chapter are what one would expect from the lead-in at the end of Chapter 1: a discussion of the possible negative, even monstrous consequences of genetic engineering. These are grouped under headings of "Evolution in the fast lane," "Narrowing of the gene pool," "Unwittingly selecting for pathogens," "Genetically engineered disease models," 
"Environmental," "Military applications," and "Socioeconomic concerns." These sections are fundamentally a catalogue of realistic dangers, with occasional commonsensical suggestions for how to try to minimize them and, in the case of military applications, a frank acknowledgment that the public, at least, is likely to have no opportunity to appraise the dangers and decide whether and, if so, how, such research should go forward.

The first ten sections of this chapter are devoted, first, to a discussion of the difficulties with doing risk assessment, particularly with new technology, and, second and consequently, to a recommendation for the formation of democratic review committees to evaluate and guide genetic engineering. Rollin is sensitive to the public distrust of scientific expertise that has developed over the past two decades and to the fundamental role of nonscientific values in reviewing research. He believes that the only way to counterbalance "the arrogance of experts," who are professionally disinclined to appropriately weigh the dangers of research, is to have local, citizen committees reviewing research proposals on a case-by-case basis. Having such committees would also both educate the public about realistic dangers-rather than fictive, Frankensteinian bogies-and provide the public reassurance that genetic engineering is not something that is being forced upon them, whether they approve or not. This public education and involvement should, Rollin believes, allay the public distrust of science, thus providing a win-win situation for both the research industry and the public.

Animal liberationists will certainly find Rollin's discussion in this chapter unsatisfying. First, his presumption is that genetic engineering is going to go forward, elsewhere even if banned in the United States. Consequently, his concern is limited to regulating how it is done. He does not consider whether the possible dangers of genetic engineering-either in general or certain kinds of it--are so great that $i /$ they should be prohibited. This "If we don't do it, somebody else will" focusing of ethical discussion on secondary, regulative issues can easily be an excuse for disregarding fundamental, moral values, and many readers may, consequently, find Rollin's discussion here shallow, even disquieting. (Interestingly, in Chapter 3, Rollin considers banning imports from countries lacking animal-welfare regulations (191); why couldn't the U.S. similarly flex its economic muscle to support prohibition?)
Second, Rollin's presumption is that the public's concern with the possibly dangerous consequences of genetic engineering is, at least in significant part, part of "the Frankenstein thing," i.e., an unrealistic concern born of ignorance about genetic engineering. Consequently, a significant part of his concern in writing this chapter and in proposing democratic review committees is to "educate" the public out of this sort of distrust of genetic engineers and engineering. Since Rollin also emphasizes healthy skepticism about self-proclaimed "expert" judgments about risk assessments, readers may wonder if approaching these public concerns as part of "the Frankenstein thing" is at all appropriate and does not represent a subtle proresearch bias. Approaching discussion of "ethical and social issues in the genetic engineering of animals" under the rubric of "The Frankenstein Syndrome" similarly bespeaks such a bias.

Third, readers who shade more toward animal liberation than animal welfare will certainly be much more skeptical than Rollin about the effectiveness of his proposed review committees. His proposal is modeled on the institutional animal care and use committees mandated by the 1985 amendments to the Animal Welfare Act. Rollin, who helped write those amendments, apparently has a high regard for how those review committees are working; many animal liberationists have a low regard for the effectiveness of those committees. Certainly, the animal research community has been able to dominate those committees, and especially given the immense financial possibilities for genetic engineering and that review committees for this research would have to govern commercial as well as public research, it is difficult to believe that the genetic engineering industry would not insure its domination of these review committees. In response to Rollin's challenge, "What other option is there?," animal liberationists would likely propose possibilities that are much less friendly_less realistic, Rollin would doubtless say- to the research community.

Chapter 3 focuses on "the plight of the creature," i.e., the welfare of animals affected by genetic engineering. Again, the chapter is divided into two discussions, the first concerning moral valuing of animals, the second concerning animal welfare problems posed by genetic engineering. While this chapter is again a defense of genetic engineering against "the Frankenstein thing"-the third aspect of this "thing" being the mistaken belief that "all genetic 
engineering must harm animals" (169)-that defense is here much more guarded. Rollin acknowledges that human prudence and self-interest in genetic engineering sometimes run contrary to what is best for the well-being of animals and that the corporate mentality underwriting the genetic engineering of animals has little interest either in animal welfare or with social concerns about animal welfare-or with any other social values that could adversely impact the efficient amassing of wealth.

Rollin begins the chapter with some very perceptive comments about how social ethics works and about the changing social ethic concerning animals. Prior to the last couple of decades, our social ethic concerning animals focused on cruelty to animals, but we now recognize that most of the suffering animals endure at our hands is not due to occasional acts of cruelty; rather, it is the byproduct of our normal way of handling animals, particularly in factory farming and biomedical research. This recognition, in the context of heightened sensitivity to all sorts of exploitation of defenseless groups, is leading us beyond anti-cruelty to a new social ethic for animals: society "now demands that we protect the animals' fundamental interests as determined by their natures" (158, a seven-fold unpacking of this on 157-8). Although we continue to fail to acknowledge an interest in staying alive to be among those fundamental interests-something Rollin passes over in silence-Western society is coming to view minimizing, if not entirely eliminating, the pain and suffering of animals at human hands to be a moral duty, one to be enforced by law and to be fulfilled even when doing so may be expensive and inconvenient.

Applying this new social ethic to genetic engineering gives rise to a regulatory principle to be employed by the review committees discussed in Chapter 2. Rollin calls this "the principle of conservation of welfare": "Any animals that are genetically engineered for human use or even for environmental benefit should be no worse off, in terms of suffering, after the new traits are introduced into the genome than the parent stock was prior to the insertion of the new genetic material" (179). Rollin discuses in considerable detail how employing this principle as law could both minimize the adverse impacts of genetic engineering on animals and reassure the public that this new industry was not developing with utter disregard of social values-again, a win-win solution. The one area of fundamental difficulty for applying this principle to such engineering occurs in the development of animals carrying the genes that cause human disorders and then studying those animals, who will be suffering from those diseases. The only way to accommodate such studies to the principle of the conservation of welfare would be, Rollin acknowledges, to find some way to render the animals nonconscious, so they could not experience the suffering that is part of the disease. In an earlier discussion of possible solutions to animal welfare problems with factory farming, Rollin opined that society would not accept such nonconscious monsters. Here, however, since the human-diseased animals would be so beneficial to us, he believes that we will want them produced no matter what the cost in animal welfare; consequently, creating such monsters is the only way to prevent this sort of genetic engineering from causing massive animal sufferingthere are 3000 human genetic disorders available for injecting into animals, and at least as many genetic engineers salivating to do so.

As always, Rollin insists on keeping ethical discussion practical. His starting point is that the genetic engineering of animals is going to continue and expand, and his concern is, then, how we can insure that the growing social commitment to minimizing animal suffering is not trampled under in the rush to the cheap food, medical miracles, and great profits promised by this new technology. Although he is optimistic that our new social ethic concerning animal welfare is strong enough to sustain significant regulation of genetic engineering for the animals' benefit, he is aware that much in our treatment of animals shows us up as "mean-spirited, self-serving, exploitative beings"(193).

The book concludes with brief discussions of animal patenting and the mechanics of genetic engineering. Rollin dismisses the patenting issue as an example of his Gresham's law for ethics: bad moral issues drive out good issues. In this case, a secondary issue has captured much media attention, even though the groundwork for deciding it has not been laid-and the attention focused on this secondary issue has diverted energy away from laying that groundwork. The groundwork is, of course, the nest of issues discussed in this book. Until we decide the social/ ethical issues Rollin raises, we cannot reasonably determine whether we should continue to regard animals as property and, even if we do so, what sorts of regulation we want to place on the use and treatment of such property. (Personally, Rollin believes that "animals should not legally be property, and the 
arguments that applied to humans not being owned apply, mutatis mutandis, to animals" (209).)

Bernie Rollin has devoted his life to ameliorating the condition of animals sacrificed in the agriculture and biomedical industries. He has thoughtfully analyzed where Western society is heading concerning animal welfare, and he has tirelessly pushed those in power to take the furthest step society is ready for toward respecting animal life and protecting animal interests. A great many animals have endured much less suffering thanks to Rollin's fine work. The Frankenstein Syndrome constitutes another important contribution to that work-and to the literature on genetic engineering in particular and practical ethics in general. While animal liberationists will find the book unsatisfying, because they do not accept Rollin's starting point--that the genetic engineering of animals is inevitable - avid genetic engineers, eager to do with their animals whatever they please, will find that Rollin is pushing for significant constraints on their work, protecting both humans and animals. They will also find that they are hard pressed to challenge the common sense and logic of his prudential social and animal welfare arguments.

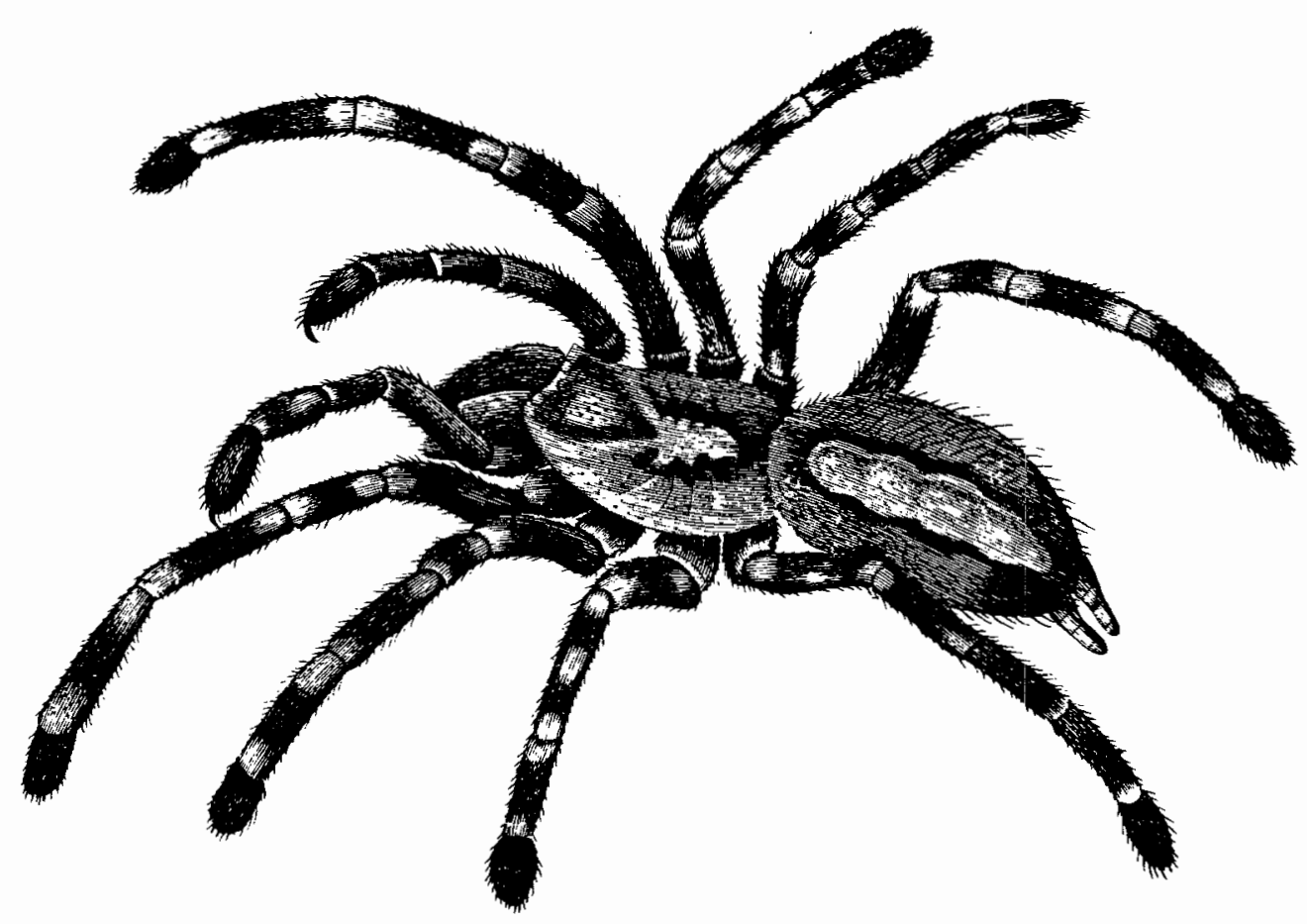

